\title{
Exercise Echocardiography in Children
}

\author{
Chen $\mathrm{CK}^{1,2 *}$ \\ ${ }^{1}$ Department of Paediatrics, National University of Singapore, Singapore \\ ${ }^{2}$ Division of Cardiology, Khoo Teck Puat-National University Children's Medical Institute, Singapore
}

*Corresponding author: Chen CK, Department of Paediatrics, Yong Loo Lin School of Medicine, National University of Singapore, 1E Kent Ridge Road, NUHS Tower Block, Singapore 119228

Submission: 監April 04, 2018; Published: 㡙 July 26, 2018

\begin{abstract}
Exercise echocardiography has been widely used in adult cardiology, and is mainly used for assessing regional myocardial function in patients with known or suspected coronary artery disease. In addition, it is also useful in the evaluation of the haemodynamic significance of valve disease, such as aortic stenosis and mitral regurgitation. In children, exercise echocardiography has found its place in the detection of ischaemia in patients with coronary artery abnormalities such as Kawasaki disease, and abnormal origin of coronary arteries. Other indications include assessment of haemodynamic and myocardial response in patients with different types of congenital heart disease, the early detection of myocardial dysfunction in specific populations such as patients after chemotherapy exposure. The incorporation of tissue Doppler and strain imaging with exercise echocardiography has allowed a more quantitative analysis of regional and global systolic and diastolic function.
\end{abstract}

Keywords: Exercise echocardiography; Children; Paediatric cardiology; Stenosis; Mitral regurgitation

Abbreviations: AS: Aortic Stenosis; TDI: Tissue Doppler Imaging; STE: Speckle Tracking Echocardiography; IVA: Isovolumic Acceleration; FFR: ForceFrequency Relationship; KD: Kawasaki Disease; ASO: Arterial Switch Operation; AS: Aortic Stenosis

\section{Introduction}

Exercise echocardiography is a well-established technique to evaluate adults with ischaemic heart disease, valvular disorder [Aortic Stenosis (AS), mitral regurgitation, and prosthetic valves], subclinical pulmonary hypertension, and for the assessment of heart function. In children, the utilization of exercise echocardiographyis relatively limited, and is mainly relegated to the realm of research. Nonetheless, it may yield important diagnostic information in paediatric heart diseases. The aim of this review is to provide a brief overview of the current utility of exercise echocardiography in children.

\section{Discussion}

Exercise echocardiography can be used in children older than8 years of age who are cooperative and able to perform an exercise test. Different methods maybe employed in the conduct of an exercise echocardiography. Treadmill exercise test with echocardiography can be achieved with image acquisition at rest and at peak exercise [1]. It is challenging to acquire images during running on the treadmill, and therefore it only allows acquisition of images during rest and at peak exercise. The other limitation of this method is the rapid attrition of heart rate whilst getting the child onto the couch for image acquisition at peak exercise, thus compromising interpretation of the results. Alternatively, the bicycle ergometer could be used. The test can be done either on an upright or a semi-supine bicycle. It permits real-time acquisition of echocardiographic images during incremental exercise [2]. Since bicycle ergometer was developed for adults, there is a minimal lower limb length requirement, thus limiting the test to taller children (generally $>8$ years of age).

Echocardiography during exercise allows qualitative assessment of global and regional myocardial function but this is highly operator-dependent. The application of Tissue Doppler Imaging (TDI) and Speckle Tracking Echocardiography (STE) to stress imaging allows quantitative evaluation of regional and global myocardial function [3]. Using TDI, peak systolic and diastolic velocities ( $\mathrm{s}^{\prime}$ and $\mathrm{e}^{\prime}$ ) can be measured at rest and during incremental exercise. Myocardial acceleration during isovolumic contraction or Isovolumic Acceleration (IVA), an index of contractility which is relatively independent of physiologic acute changes in preload and after load, can also be measured with colour TDI [4]. Figure 1 provides an example of offline measurement of colour TDI velocities and IVA in a healthy child. As myocardial contractile force increases with incremental HR (Treppe effect), expressing IVA vs. HR has been proposed as a method for non-invasively assessing the Force-Frequency Relationship (FFR) [5]. One of the advantages of IVA is its ability to respond to instantaneous changes in force 
development, such as those that occur in response to heart rate. A flattened FFR curve as exemplified by an abnormal IVA response during exercise is indicative of a decreased contractile reserve. On the other hand, STE allows quantification of regional myocardial deformation by calculating strain and strain rate, and has been applied in paediatric heart disease [6].
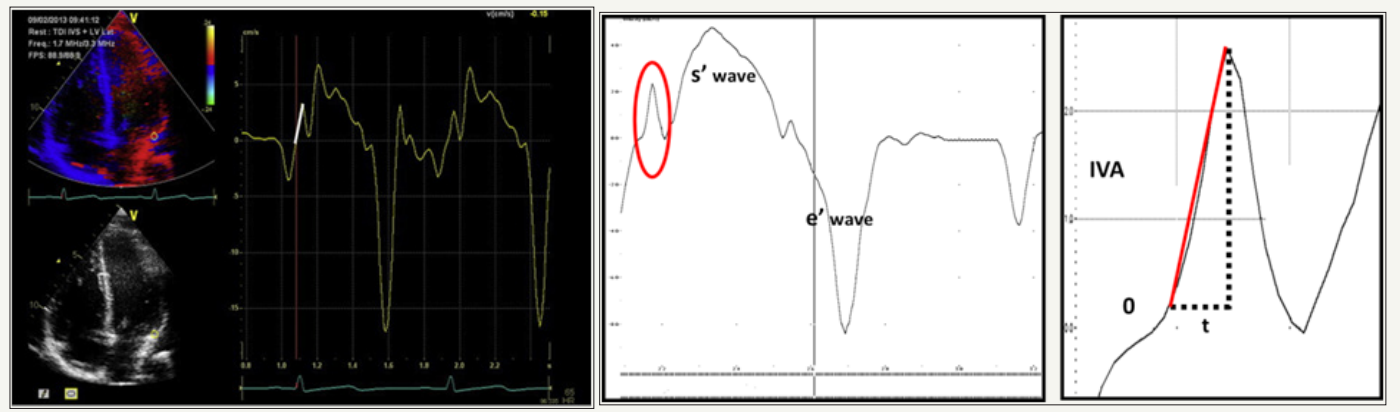

Figure 1: Colour tissue Doppler s', e' and measurement of IVA. The vertical line describes the onset of IVA, which coincides with the $\mathrm{R}$ wave on the electrocardiogram. IVA was calculated as the difference between baseline and peak velocity divided by their time interval.

The application of exercise echocardiography in paediatric heart disease is still in evolution with changing indications. In children, the most common indication for exercise echocardiography is children at risk for ischaemic heart disease. These include children who had Kawasaki Disease (KD), those with anomalous coronary artery origin or after coronary re-implantation (e.g. arterial switch operation, Ross operation). KD is the commonest acquired paediatric heart disease in developed countries. As sequelae of KD, coronary aneurysms may develop, with the risk of thrombosis and its consequent myocardial ischaemia and infarction [7]. Current guidelines recommend the use of stress imaging for the clinical follow-up and risk stratification of patients with isolated small-tomedium coronary artery aneurysms in at least 1 coronary artery on echocardiography or angiography (class III), patients with at least 1 large coronary artery aneurysm including giant aneurysms, patients with multiple or complex aneurysms without obstruction (class IV), and in patients with coronary artery obstruction confirmed by angiography (Class V) [8]. Pahl and colleagues used exercise echocardiography to evaluate children with coronary artery involvement secondary to KD. Two children developed exerciseinduced wall motion abnormalities, and were subsequently found to have critical stenosis of the left anterior descending coronary artery on angiography [9]. By measuring M-modemitral annulus excursion during exercise echocardiography, Henein and colleagues demonstrated a reduction in LV longitudinal systolic function in children with KD when compared with controls [10]. Coronary artery abnormalities may occur in children with transposition of the great arteries who had undergone Arterial Switch Operation (ASO), which involves translocation of the coronary arteries. Coronary artery stenosis and occlusion have been demonstrated by angiography and computed tomography in up to $5-7 \%$ of these patients [1113]. As the implication of some of the coronary lesions may be uncertain, exercise echocardiography can be used in children after ASO to detect ischaemia. Using exercise echocardiography, Chen and colleagues demonstrated reduced contractile response to exercise in children after ASO compared with controls, by constructing FFR curves based on LV IVA. In addition, they also noted a reduced diastolic response in tissue Doppler-derived e' velocity [14]. A rare cause of ischaemic heart disease in children is the anomalous origin and/or course of a coronary artery, which can be associated with an intramural or inter arterial course of the proximal coronary artery. This puts the patient at risk of myocardial ischaemia and sudden death $[15,16]$. The clinical management of these often asymptomatic patients remains controversial [17]. Stress testing is generally considered a useful tool in the diagnostic work-up of these patients. Brothers and colleagues, using a multimodality approach including exercise stress test, stress echocardiography, and stress myocardial perfusion scan, demonstrated findings suggestive of ischaemic changes in some children with anomalous aortic origin of coronary artery after surgical repair. The authors advocated for a multimodality approach in these patients, given the intermittent nature of such ischaemic episodes [18].

A next potential indication for exercise echocardiography is the assessment of dynamic pressure gradientin the contextof obstructive lesions. For valvular heart disease, exercise echocardiography has been shown to yield prognostic information in adults with asymptomatic severe Aortic Stenosis (AS) [19]. However, there are no data available in children. Naik and colleagues performed exercise echocardiography in children with AS, and reported the presence of regional wall motion abnormalities associated with ST-segment depression. However, the clinical significance of such findings remain uncertain as some of these children only had mild AS at rest [20]. In children, the effect of exercise on dynamic Left Ventricular Outflow Tract (LVOT) obstruction has been evaluated mainly in patients with Hypertrophic Cardiomyopathy (HCM). A significant number of HCM patients have no obstruction at rest, but can develop significant dynamic LVOT gradients during exercise [21,22]. In the ACCF/AHA guidelines for the diagnosis and treatment of HCM, exercise echocardiography is included as a class IIa recommendation for the detection and quantification of exercise-induced dynamic LVOT obstruction in adults who have a resting peak gradient of $<50 \mathrm{mmHg}$ (level of evidence B) [23]. In children, such practice may be controversial as Wittlieb-Weber and colleagues recently demonstrated that, in normal subjects, high exercise-induced LVOT velocities may be observed and should be considered a normal physiological finding in healthy children 
and adolescents [24]. It is therefore unclear how this affects the interpretation of exercise data for children with HCM. Exercise echocardiography has also been employed for the assessment of residual gradients in children after repair of aortic coarctation $[25,26]$. Recoarctation can be difficult to diagnose but the clinical significance of residual mildgradients across the aortic arch or transverse aorta remains unclear. Be that as it may, the detection of a significant arch gradient during exercise coupled with arterial hypertension proximal to the stenosis is a relevant clinical finding that may require further investigation and treatment. Furthermore, a significant proportion of children who had undergone stent implantation for aortic coarctation or recoarctation have been reported to have an abnormal blood pressure response [27].

Last but not least, exercise echocardiography can be used to study early changes in myocardial function by evaluating the systolic and diastolic response to exercise. Oftentimes, early myocardial injury may be difficult to detect at rest since the myocardium uses different compensatory mechanisms to maintain pump function. A decreased systolic or diastolic response to exercise may be the first sign of early myocardial dysfunction. Therefore, patients with signs of early dysfunction may require more regular surveillance compared to those with preserved stress response. This approach could potentially be applied to children who are at increased risk of developing heart failure but with normal heart function and chamber size (Stage A heart failure) e.g. exposure of cardiotoxic agents, family history of cardiomyopathy, congenital heart disease such as single ventricle anatomy etc. There have been a few studies evaluating the exercise response in childhood cancer survivors $[28,29]$. In asymptomatic survivors at least 5 years after cancer treatment, Ryerson and colleagues demonstrated mild diastolic abnormalities at rest which disappeared during exercise [30]. Sieswerda and colleagues studied the predictive value of peak exercise Ejection Fraction (EF) in asymptomatic anthracyclinetreated childhood cancer survivors [31]. They concluded that peak exercise EF did not predict reduction of EF after 10 years of follow-up. As EF can be maintained in damaged myocardium due to compensatory mechanisms, research into early markers of myocardial dysfunction could potentially be more useful. At 10year follow-up, anthracycline-treated childhood cancer survivors with preserved resting EF at rest demonstrated mildly blunted systolic LV IVA response and mildly lower diastolic tissue Doppler velocities during exercise when compared to normal subjects [32]. Children with HCM also demonstrated reduced systolic and diastolic functional reserve, which was unrelated to the degree of outflow obstruction [33]. However, this technique was not found to be discriminatory in children with hypertrabeculation of the LV myocardium and those with left ventricular non-compaction who have normal baseline heart function [34]. In the realm of congenital heart disease, exercise stress echocardiography unveiled abnormal systolic and diastolic reserve, as well as a reduced contractile response to exercise in young patients who had undergone endovascular stenting of aortic coarctation in childhood [35].

\section{Conclusion}

Exercise echocardiography is potentially an emerging cardiovascular assessment tool in children.

The introduction of tissue Doppler and myocardial deformation imaging offers a more quantitative approach to the evaluation of global and regional systolic and diastolic response to exercise. This modality is preferred in children above 8 years of age, and is currently mainly used for assessing children with coronary artery abnormalities. Other indications include valve disorders, coarctation of the aorta, and assessment of myocardial reserve.

\section{Conflict of Interest}

The author has no conflict of interest to disclose.

\section{References}

1. Hasan BS, Lunze FI, McElhinney DB, Stantcheva E, Brown DW, et al. (2012) Exercise stress echocardiographic assessment of outflow tract and ventricular function in patients with an obstructed right ventricularto-pulmonary artery conduit after repair of conotruncal heart defects. Am J Cardiol 110(10): 1527-1533.

2. Hecht HS, DeBord L, Sotomayor N, Shaw R, Dunlap R, et al. (1993) Supine bicycle stress echocardiography: peak exercise imaging is superior to post-exercise imaging. J Am Soc Echocardiogr 6(3 Pt 1): 265-271.

3. Cifra B, Dragulescu A, Brun H, Slorach C, Friedberg MK, et al. (2014) Left ventricular myocardial response to exercise in children after heart transplant. J Heart Lung Transplant 33(12): 1241-1247.

4. Vogel M, Cheung MM, Li J, Kristiansen SB, Schmidt MR, et al. (2003) Noninvasive assessment of left ventricular force-frequency relationships using tissue Doppler-derived isovolumic acceleration: validation in an animal model. Circulation 107(12): 1647-52.

5. Roche SL, Vogel M, Pitkanen O, Grant B, Slorach C, et al. (2011) Isovolumic acceleration at rest and during exercise in children normal values for the left ventricle and first non-invasive demonstration of exercise-induced force-frequency relationships. J Am Coll Cardiol 57(9): 1100-1107.

6. Friedberg MK, Mertens L (2012) Deformation imaging in selected congenital heart disease: is it evolving to clinical use? J Am Soc Echocardiogr 25(9): 919-931.

7. Onouchi Z, Hamaoka K, Sakata K, Ozawa S, Shiraishi I, et al. (2005) Longterm changes in coronary artery aneurysms in patients with Kawasaki disease: comparison of therapeutic regimens. Circ J 69(3): 265-272.

8. Mc Crindle BW, Rowley AH, Newburger JW, Burns JC, Bolger AF, et al. (2017) Diagnosis, Treatment, and Long-Term Management of Kawasaki Disease: A Scientific Statement for Health Professionals From the American Heart Association. Circulation 135(17): e927-e999.

9. Pahl E, Sehgal R, Chrystof D, Neches WH, Webb CL, etal. (1995) Feasibility of exercise stress echocardiography for the follow-up of children with coronary involvement secondary to Kawasaki disease. Circulation 91(1): 122-128.

10. Henein MY, Dinarevic S, O'Sullivan CA, Gibson DG, Shinebourne EA, et al. (1998) Exercise echocardiography in children with Kawasaki disease: ventricular long axis is selectively abnormal. Am J Cardiol 81(11): 13561359.

11. Bonhoeffer P, Bonnet D, Piechaud JF, Stumper O, Aggoun Y, et al. (1997) Coronary artery obstruction after the arterial switch operation for transposition of the great arteries in newborns. J Am Coll Cardiol 29(1): 202-206. 
12. Ou P, Celermajer DS, Marini D, Agnoletti G, Vouhe P, et al. (2008) Safety and accuracy of 64-slice computed tomography coronary angiography in children after the arterial switch operation for transposition of the great arteries. JACC Cardiovasc Imaging 1(3): 331-339.

13. Ou P, Khraiche D, Celermajer DS, Agnoletti G, Le Quan KH, et al. (2013) Mechanisms of coronary complications after the arterial switch for transposition of the great arteries. J Thorac Cardiovasc Surg 145(5): 1263-1269.

14. Chen RH, Wong SJ, Wong WH, Cheung YF (2013) Left ventricular contractile reserve after arterial switch operation for complete transposition of the great arteries:an exercise echocardiographic study. Eur Heart J Cardiovasc Imaging 14(5): 480-486.

15. Basso C, Maron BJ, Corrado D, Thiene G (2000) Clinical profile of congenital coronaryartery anomalies with origin from the wrong aortic sinus leading to sudden death in young competitive athletes. J Am Coll Cardiol 35(6): 1493-1501.

16. Frommelt PC, Berger S, Pelech AN, Bergstrom S, Williamson JG, et al. (2001) Prospective Identification of anomalous origin of left coronary artery from the right sinus of Valsalva using transthoracic echocardiography: importance of colour Doppler flow mapping. Pediatr Cardiol 22(4): 327-332.

17. Graham TP, Driscoll DJ, Gersony WM, Newburger JW, Rocchini A, et al. (2005) Task Force 2: Congenital Heart Disease. J Am Coll Cardiol 45(8): 1326-1333.

18. Brothers JA, McBride MG, Seliem MA, Marino BS, Tomlinson RS, et al (2007) Evaluation of myocardial ischemia after surgical repair of anomalous aortic origin of a coronary artery in a series of pediatric patients. J Am Coll Cardiol 50(21): 2078-2082.

19. Magne J, Lancellotti P, Pierard LA (2014) Exercise testing in asymptomatic severe aortic stenosis. JACC Cardiovasc Imaging 7(2): 188-199.

20. Naik R, Kunselman A, Wackerle E, Johnson G, Cyran SE, et al. Stress echocardiography: a useful tool for children with aortic stenosis. Pediatr Cardiol 34(5): 1237-1243.

21. Joshi S, Patel UK, Yao SS, Castenada V, Isambert A, et al. (2011) Standing and exercise Doppler echocardiography in obstructive hypertrophic cardiomyopathy: the range of gradients with upright activity. J Am Soc Echocardiogr 24(1): 75-82.

22. Shah JS, Esteban MT, Thaman R, Sharma R, Mist B, et al. (2008) Prevalence of exercise-induced left ventricular outflow tract obstruction in symptomatic patients with non-obstructive hypertrophic cardiomyopathy. Heart 94(10): 1288-1294.

23. Gersh BJ, Maron BJ, Bonow RO, Dearani JA, Fifer MA, et al. (2011) 2011 ACCF/AHA Guideline for the Diagnosis and Treatment of Hypertrophic Cardiomyopathy: a report of the American College of Cardiology Foundation/American Heart Association Task Force on Practice Guidelines. Developed in collaboration with the American Association for Thoracic Surgery, American Society of Echocardiography, American Society of Nuclear Cardiology, Heart Failure Society of America,
Heart Rhythm Society, Society for Cardiovascular Angiography and Interventions, and Society of Thoracic Surgeons. I Am Coll Cardiol 58(25): e212-260

24. Wittlieb-Weber CA, Cohen MS, McBride MG, Paridon SM, Morrow R, et al. (2013) Elevated left ventricular outflow tract velocities on exercise stress echocardiography may be a normal physiologic response in healthy youth. J Am Soc Echocardiogr 26(12): 1372-1378.

25. Guenthard J, Wyler F (1996) Doppler echocardiography during exercise to predict residual narrowing of the aorta after coarctation resection. Pediatr Cardiol 17(6): 370-374.

26. Mori F, Favilli S, Zuppiroli A, Minneci C, Cupelli V, et al. (1993) [The sports fitness of patients operated on for aortic coarctation: assessment by exercise Doppler echocardiography]. G Ital Cardiol 23(3): 225-237.

27. Morgan GJ, Lee KJ, Chaturvedi R, Bradley T], Mertens L, et al. Systemic blood pressure after stent management for arch coarctation implications for clinical care. JACC Cardiovasc Interv 6(2):192-201.

28. Smibert E, Carlin JB, Vidmar S, Wilkinson LC, Newton M et al. (2004) Exercise echocardiography reflects cumulative anthracycline exposure during childhood. Pediatr Blood Cancer 42(7): 556-562.

29. De Souza AM, Potts JE, Potts MT, De Souza ES, Rowland TW, et al. (2007) A stress echocardiography study of cardiac function during progressive exercise in pediatric oncology patients treated with anthracyclines. Pediatr Blood Cancer 49(1): 56-64.

30. Ryerson AB, Border WL, Wasilewski-Masker K, Goodman M, Meacham L, et al. (2015) Assessing anthracycline-treated childhood cancer survivors with advanced stress echocardiography. Pediatr Blood Cancer 62(3): 502-508

31. Sieswerda E, Kremer LC, Vidmar S, De Bruin ML, Smibert E, et al. (2010) Exercise echocardiography in asymptomatic survivors of childhood cancer treated with anthracyclines: a prospective follow-up study. Pediatr Blood Cancer 54(4): 579-584

32. Cifra B, Chen CK, Fan CS, Slorach C, Manlhiot C, et al. (2018) Dynamic Myocardial Response to Exercise in Childhood Cancer Survivors Treated with Anthracyclines. J Am Soc Echocardiogr.

33. Cifra B, Dragulescu A, Friedberg M, Benson L, Mertens L, et al. (2013) Exercise stress echocardiography in children with hypertrophic cardiomyopathy. In: The $24^{\text {th }}$ Annual ASE Scientific Sessions Minneapolis, USA

34. Chen CK, Cifra B, Slorach C, Fan CS, Manlhiot C, et al. (2018) Dynamic Myocardial Response to Exercise in Children with Isolated Noncompaction of the Left Ventricular Myocardium. In: The $38^{\text {th }}$ International Society of Heart and Lung Transplantation (ISHLT) Annual Meetings and Scientific Sessions; Nice, France.

35. Chen CK, Cifra B, Morgan GJ, Sarkola T, Slorach C, et al. (2016) Left Ventricular Myocardial and Hemodynamic Response to Exercise in Young Patients after Endovascular Stenting for Aortic Coarctation. J Am Soc Echocardiogr 29(3): 237-246
Creative Commons Attribution 4.0 International License

For possible submissions Click Here

\section{Submit Article}

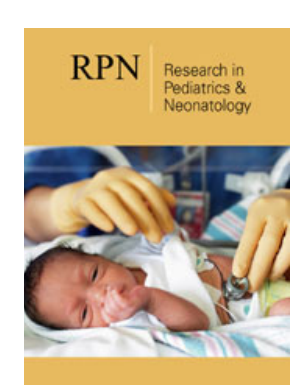

\section{Research in Pediatrics \& Neonatology}

\section{Benefits of Publishing with us}

- High-level peer review and editorial services

- Freely accessible online immediately upon publication

- Authors retain the copyright to their work

- Licensing it under a Creative Commons license

- Visibility through different online platforms 